\title{
Complete plastic lining of the abdominal cavity during laparoscopic electromechanical morcellation-a promising technique
}

\author{
Henrik Halvor Springborg • Olav Istre
}

Received: 30 December 2014 / Accepted: 14 January 2015 / Published online: 27 January 2015

(C) Springer-Verlag Berlin Heidelberg 2015

\begin{abstract}
The risk of intraperitoneal fragment dissemination of uterine tissue, especially the dissemination of unexpected leiomyosarcoma during electromechanical morcellation, has been increasingly debated during the last year. An improved technique for contained morcellation of uterine tissue inside an insufflated plastic bag during laparoscopy is presented. Twenty-one consecutive contained morcellations were carried out during the summer of 2014, at one institution. Five laparoscopic myomectomies and 16 hysterectomies were performed. Standard laparoscopic equipment was used and a transparent plastic bag was introduced into the abdominal cavity through the umbilical incision mounted on two curved blunt metal probes, which facilitated the placement of the uterine tissue into the bag. Morcellation was carried out inside the plastic bag through the opening in the umbilicus. All 21 morcellations during the study period were successfully performed. The median operative time was 105 min (range 45$180 \mathrm{~min}$ ) and applying plastic bag and trocar median $10 \mathrm{~min}$ (range 4-30 min). Median specimen weight was $560 \mathrm{~g}$ (range $80-1265$ g). No complications occurred, and no unintended bag perforation was identified. The presented improved contained morcellation technique is feasible in laparoscopic hysterectomy and myomectomy. Larger studies will however be required before the general introduction of the method.

Level of evidence: II-3
\end{abstract}

Tweetable abstract Twenty-one successful contained morcellations of uterine tissue during laparoscopic surgery are reported.

\footnotetext{
H. H. Springborg $(\bowtie) \cdot$ O. Istre

Department of Minimal Invasive Gynaecology, Aleris Hamlet

Hospital, Gyngemose Parkvej 66, 2860 Soeborg,

Copenhagen, Denmark

e-mail: henrik.springborg@aleris-hamlet.dk

O. Istre

Center of Gynaecology, University of Southern Denmark,

Odense, Denmark
}

Keywords Minimal invasive gynaecology $\cdot$ Morcellation · Leiomyosarcoma $\cdot$ Laparoscopic hysterectomy . Laparoscopic $\cdot$ Myomectomy $\cdot$ Uterine Fibroids

\section{Introduction}

Dissemination of benign myoma after electromechanical morcellation is a known complication and is estimated to occur after 0.1 to $1 \%$ of procedures. The fragments of uterine tissue left in the abdomen can cause the implantation of fibroma, infection, pain and the need for reoperation [1-3]. The unintended morcellation of uterine leiomyosarcoma is of even greater concern and is suspected to worsen prognosis [4-6]. It is estimated that between 1:400 and 1:1000 hysterectomy specimens for presumed benign myoma will ultimately be confirmed as leiomyosarcoma [7]. These rare but serious problems not only occur in relation to electromechanical morcellation but probably also during manual morcellation through the vagina or mini-laparotomy. The cleaning and irrigation of the abdominal cavity after traditional electromechanical morcellation are often difficult and time consuming. Morcellation in an inflated transparent plastic bag may reduce these problems. The method may even reduce the risk of the unintended morcellation of the bowel since the bowel is kept away by the plastic bag, which lies flush against all aspects of the abdominal cavity during morcellation.

Morcellation is of great importance in benign gynaecological laparoscopic surgery. In laparoscopic myomectomy and supracervical hysterectomy, it is imperative. In total laparoscopic hysterectomy, morcellation is also required when the uterus, due to size, cannot be removed by the vaginal route. The US Food and Drug Administration (FDA) approved the first electromechanical morcellator in 1995. 
During the latest years, the risk of intraperitoneal fragment dissemination, especially the dissemination of unexpected leiomyosarcoma, has been debated $[1,4,6]$, and the US Food and Drug Administration in April 2014 issued a statement discouraging the use of electromechanical morcellation in most cases [7]. AAGL emphasizes in the report "Morcellation During Uterine Tissue Extraction" from May 2014 the great demand for a contained morcellation system and instrumentation to facilitate the safe removal of specimens [8]. It will be a great setback for minimal invasive gynaecology if laparotomy has to be reintroduced as a standard treatment for many benign gynaecological diseases.

In this report, we describe an innovative feasible technique to place and morcellate uterine and myoma tissue in a specimen retrieval pouch during laparoscopic procedures. Cohen et al. have recently described a technique for contained power morcellation [10]. Our study confirms the feasibility of the technique, presented by Cohen et al., and introduces additional improvement of the minimally invasive specimen retrieval technique.

\section{Materials and methods}

Twenty-one consecutive patients underwent uterine tissue morcellation from June to September 2014 for the removal of uterine tissue during laparoscopic myomectomy or laparoscopic hysterectomy at Aleris Hamlet Hospital in Copenhagen, Denmark. All morcellations were performed in a plastic bag, and no laparotomy was performed. The described technique is now a standard procedure at our institution, when removal of uterine tissue requires morcellation during laparoscopy. Informed consent was obtained from all patients for being included in the study.

The preoperative workup to evaluate risk of genital tract cancer included a recent Pap test, endometrial sampling in cases of irregular bleeding and imaging with abdominal and pelvic ultrasonography. Demographic information included patient age, obstetric history, body mass index, physical status, surgical history and indication for surgery. Perioperative information collected prospectively included type of procedure performed, operative time (time from incision to closure), time for placing bag in the abdomen including placement of uterine tissue in the bag and time for placing lateral port in bag (representing extra time used for performing this technique), estimated blood loss (anaesthetic nurse estimate recorded in the operative record), specimen weight, intact status of specimen retrieval pouch (obtained by visual inspection of the bag by the surgeon), length of hospital stay, intraoperative complications, readmission to hospital and reoperation.

A 12-mm port is placed in the umbilicus and additional three 5-mm ports. Two are placed on the level of the umbilicus, laterally on both sides, and one port approximately $6 \mathrm{~cm}$ above the umbilicus in the midline, in order to give a good overview when placing the bag (Fig. 1). To avoid slippage of the right lateral trocar from its location within the isolation bag and avoid spillage during morcellation, a balloon-tipped 5$\mathrm{mm}$ trocar (Kii Fios, Applied Medical, Rancho Santa Margarita, CA, USA) is used (Fig. 2). Morcellation is performed with a reusable electromechanical 15 or $20 \mathrm{~mm}$ morcellator (Wolf, Hamburg, Germany) (Fig. 1). A standard $30^{\circ} 5$-mm optic (Olympus, Hamburg, Germany) is used enabling us to port jump. The plastic bag used is a standard ( 8 Euro) plastic isolation/transport bag $47 \mathrm{~cm} \times 46 \mathrm{~cm}$, with a strap in the rim, normally used for bowel placement during laparotomy (Microtec Medical, Zutphen Netherlands).

The plastic isolation bag, mounted on two curved blunt metal probes, is inserted through a $2-\mathrm{cm}$ incision in the umbilicus after the laparoscopic hysterectomy or myomectomy (Fig. 3a, b). Inside the abdomen, the upper metal probe is turned $180^{\circ}$, and the two probes in the rim of the bag forms a ring like a traditional "endobag" which facilitates the placement of the uterine tissue into the bag (Fig. 3c, d). After the placement of the tissue in the bag, the strap in the rim of the bag is pulled back, the probes are retracted at the same time and the opening of the bag is brought extra-abdominally. A blunt 12-mm trocar is introduced through the opening of the bag in the umbilicus, and the bag is insufflated under laparoscopic guidance. The space outside the bag is desufflated through the vents of the other ports. When fully inflated, visual inspection through the $12-\mathrm{mm}$ trocar is carried out to confirm that the uterine tissue is located inside the plastic bag and to check that the bag fully lines the abdominal cavity.

To facilitate insufflation and continuous laparoscopic visualization during the insertion of the morcellator through the umbilical incision, the inflated bag is pierced by the $5-\mathrm{mm}$ balloon-tipped trocar in the right lateral port and the balloon tip is insufflated (Fig. 2). In order to facilitate the penetration of the plastic bag and to avoid lesions in the bowel, which may be relocated during the insufflation of the bag, a special technique is recommended: The tip of the balloon-tipped right

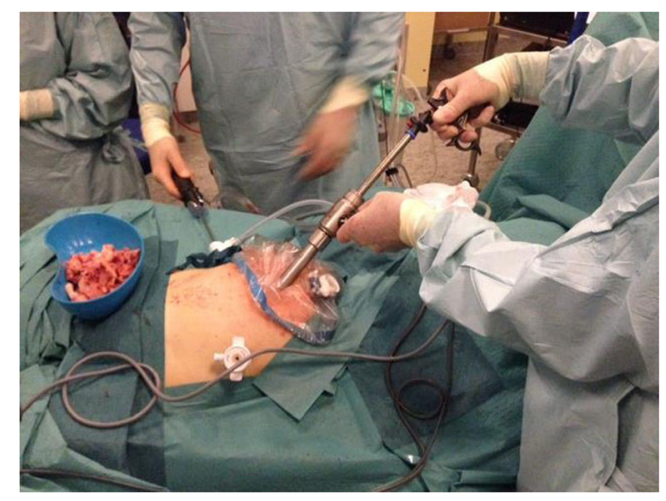

Fig. 1 Feasible placement of trocars during morcellation 


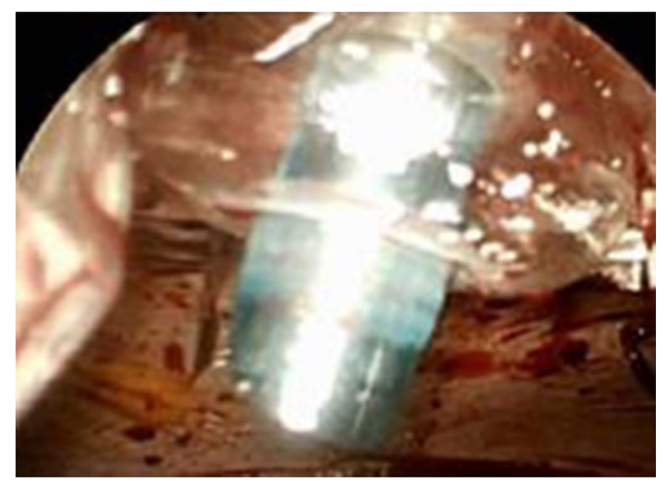

Fig. 2 A 5-mm balloon-tipped trocar (right lateral port)

lateral $5-\mathrm{mm}$ trocar is inserted into the tube of the $12-\mathrm{mm}$ trocar, visually guided by the 5-mm optic located in the 12 $\mathrm{mm}$ trocar. When the two trocars are aligned, the optic is withdrawn, the 5-mm trocar is inserted into the tube of the $12-\mathrm{mm}$ trocar and the plastic bag is easily penetrated. The balloon tip is then inflated again while retracting the $5-\mathrm{mm}$ port from the tube of the $12-\mathrm{mm}$ port. The defect in the bag is now "sealed" by the balloon (Fig. 2). The 5-mm optic and $\mathrm{CO}_{2}$ insufflation are shifted to the right lateral $5-\mathrm{mm}$ port. The $12-\mathrm{mm}$ trocar is removed from the bag, and the morcellator device is introduced into the inflated bag through the umbilical incision. The morcellation is now performed under continuous laparoscopic visualization, and all remnants and blood are captured in the bag (Fig. 4). After morcellation, the lateral $5-\mathrm{mm}$ trocar is removed after deflation of the tip, and the plastic bag is removed and tested for perforations. After the specimen is removed, a laparoscopic survey of the abdomen and pelvis is performed in order to watch haemostasis and secure that no morcellated tissue has escaped the bag.

\section{Statistics}

Descriptive statistics were performed using Microsoft Office Excel 2013. Median and range are presented for continuous

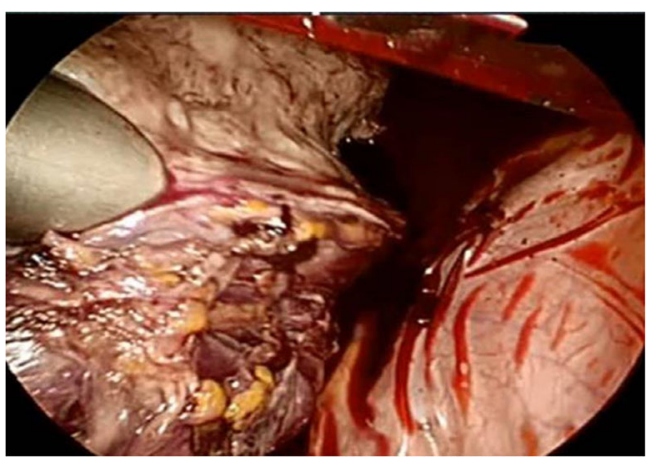

Fig. 4 Electromechanical morcellation in plastic bag

variables. Categorical variables are presented as a number and percentage.

\section{Results}

Twenty-one consecutive cases of uterine morcellation were performed during the study period. Table 1 summarizes the baseline characteristics. The median patient age was 45 years (range 38-53 years), median body mass index (BMI) was 23 (range 20-30), median physical status (ASA) 1 (range 1-2) and median parity 1 (range $0-3$ ). Prior abdominal surgery was noticed in $43 \%$ of the patients. Table 2 summarizes the operative characteristics and outcome. Leiomyoma was the indication for the procedure in all cases, in combination with pain in 16 cases and bleeding disorders in 10 cases.

Total laparoscopic hysterectomy was performed in 2 patients, in 12 patients supracervical laparoscopic hysterectomy and in 5 patients a myomectomy. Nearly half of the cases included salpingectomy and $19 \%$ oophorectomy or cystectomy. Major adhesiolysis were performed in $24 \%$ of the cases.

Operative outcomes included mean operation time of $105 \mathrm{~min}$ (range 45-180 min). Mean time used for introducing the plastic bag into the abdomen, manipulating the uterine specimen into the bag, insufflating the bag and placement of

Fig. 3 Instrumentation for introduction of bag in the abdomen and placement of tissue in the bag. a Two parallel curved blunt uterine probes enabling insertion of the plastic bag through a $2-\mathrm{cm}$ incision. b Probes placed in the rim of the plastic bag ready to be inserted in the abdomen. c Turning one probe $180^{\circ}$ demonstrated without bag. d The bag is opened and the tissue can easily be brought into the bag
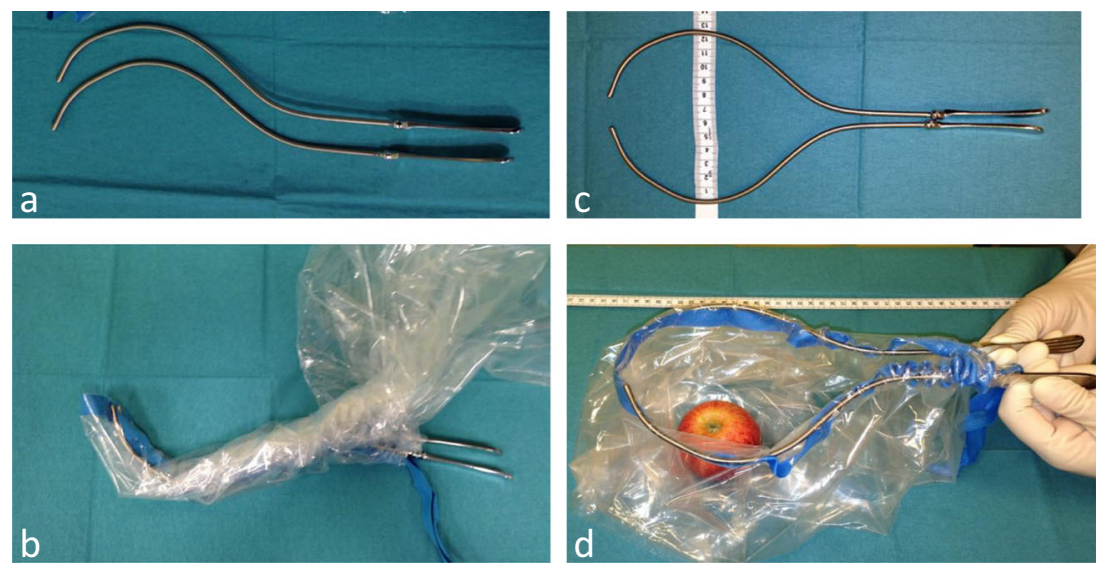
Table 1 Baseline characteristics of study population $(N=21)$

\begin{tabular}{ll}
\hline Characteristic & Value \\
\hline Age (years) & $45(38-53)$ \\
Body mass index (BMI) $\left(\mathrm{kg} / \mathrm{m}^{2}\right)$ & $23(20-30)$ \\
ASA & $1(1-2)$ \\
Parity & $1(0-3)$ \\
Prior abdominal surgery & \\
$\quad$ None & $12(57)$ \\
Laparoscopy & $3(14)$ \\
Laparotomy & $6(29)$ \\
\hline
\end{tabular}

Data are median (range) or $n(\%)$

$A S A$ American Society of Anaesthesiologists physical status classification system

the $5 \mathrm{~mm}$ trocar for gas and optic was $10 \mathrm{~min}$ (range 4$30 \mathrm{~min}$ ). During the first 11 operations, the mean time used

Table 2 Operative characteristics and outcomes of study population $(N=21)$

\begin{tabular}{ll}
\hline Characteristic or outcome & Value \\
\hline Surgical indications & \\
$\quad$ Leiomyoma & \\
Abnormal bleeding & $21(100)$ \\
Pelvic pain & $10(48)$ \\
Other & $16(76)$ \\
Procedure & $2(14)$ \\
Supracervical laparoscopic hysterectomy & \\
Total laparoscopic hysterectomy & $14(67)$ \\
Myomectomy & $2(10)$ \\
Additional procedures & $5(24)$ \\
Adnexal removal or cystectomy & \\
Salpingectomy & $4(19)$ \\
Adhesiolysis & $9(43)$ \\
Operative time (min) & $5(24)$ \\
Time for applying bag and trocar & $105(45-180)$ \\
All 21 patients (min) & \\
First 11 patients (min) & $10(4-30)$ \\
Last 10 patients (min) & $16(7-30)^{\mathrm{c}}$ \\
Estimated blood loss (ml) & $7(4-13)^{\mathrm{c}}$ \\
Specimen weight $(\mathrm{g})$ & $80(10-500)$ \\
Bag intact at end of procedure & $560(80-1265)$ \\
Length of hospital stay & $21(100)$ \\
$<24$ h & $20(95)$ \\
$24-48$ h & $1(5)$ \\
\hline & \\
&
\end{tabular}

Data are median (range) or $n(\%)$

${ }^{\text {a }}$ Categories not mutually exclusive

${ }^{\mathrm{b}}$ Total time used for introducing the bag into the abdomen, manipulating the uterine specimen into the bag, insufflating the bag and placement of the 5-mm balloon-tipped trocar for gas and optic

${ }^{\mathrm{c}}$ Statistical analysis not performed since the patients were not compareable was $16 \mathrm{~min}$ and the last 10 operations was $7 \mathrm{~min}$. The patients and procedures were not directly comparable; however, the reduction in time consumption indicates a considerable learning curve. Median estimated blood loss was $80 \mathrm{ml}$ and median specimen weight was $560 \mathrm{~g}$ (range 80-1265 g). No complications occurred; furthermore, no conversion to laparotomy or repeat surgery and all patients except one were discharged the following morning. One patient stayed 2 days in the hospital for a headache. All retrieval pouches were removed without macroscopic spillage, and the technique was successful with complete morcellation in all 21 cases. No bag perforation was identified, except the 5-mm intended puncture site for inspection and gas insufflation.

\section{Discussion}

In this study, we have demonstrated a feasible method, enabling the gynaecologist to continue minimal invasive surgery without risk of dissemination, even when treating larger uterine myomas. The operating time was not increased, because although insertion of the bag was time consuming (mean $10 \mathrm{~min}$ ), time at the end was saved because of less need of cleaning and irrigating of the abdominal cavity for remnants of tissue fragments and blood.

The strengths of this study are that all morcellations of uterine tissue performed in the study period were contained in a plastic bag and no laparotomy was needed in the study period. The use of the balloon-tipped trocar prevented leakage from the perforation in the bag, and the visually controlled method of introducing the trocar in the plastic bag prevents bowel perforation during insertion. The procedure was furthermore based on standard laparoscopic equipment and with very low cost. Weaknesses include the small study size and that only two surgeons performed all operations. The deliberate perforation of the plastic bag by the trocar may cause unintended leakage of fluid and tissue despite the "sealing effect" of the balloon trocar. A small in vitro study of contained morcellation in a plastic bag similar to the one used in this study, however, suggests that the technique can effectively decrease or potentially eradicate tissue spillage [9]. A prospective cohort multicentre study, including 200 patients, is planned in Denmark to evaluate the safety and feasibility of the method.

The results in the multicentre cohort study of Cohen et al. [10], combined with the results of this study, confirm that morcellation of uterine tissue within a specimen retrieval pouch is feasible. Both techniques are based on the use of an inflated large bag made of clear plastic drape film. This results in a large intraabdominal space where bowel is kept away and morcellation is easily performed. The technique will probably be the basis of further development of contained morcellation. 
Acknowledgments We thank Senior Consultant, MD, PhD, Lars Franch Andersen, for proofreading the manuscript.

Funding None.

Conflict of interest Henrik Halvor Springborg declares that he has no conflict of interest. Olav Istre declares that he has no conflict of interest.

Details of ethic approval All procedures followed were in accordance with the ethical standards of the responsible committee on human experimentation at our institution, Aleris-Hamlet Hospital Scandinavia, and with the Helsinki Declaration of 1975, as revised in 2000 [5]. Informed consent was obtained from all patients for being included in the study.

Details of the contributions of individual authors Both authors contributed pertinent aspects of the planning, conducting and reporting of the work described in the article.

\section{References}

1. Heller DS, Cracchiole B (2014) Peritoneal nodules after laparoscopic surgery with uterine morcellation: review of a rare complication. J Minim Invasive Gynecol 21:384-388

2. Leren V, Langebrekke A, Qvigstad E (2012) Parasitic leiomyomas after laparoscopic surgery with morcellation. Acta Obstet Gynecol Scand 91:1233-1236
3. Cucinella G, Granese R, Calagna G, Somigliana E, Perino A (2011) Parasitic myomas after laparoscopic surgery: an emerging complication in the use of morcellator? Description of four cases. Fertil Steril 96:e90-e96

4. Park JY, Park SK, Kim DY, Kim JH, Kim YM, Kim YT et al (2011) The impact of tumor morcellation during surgery on the prognosis of patients with apparently early uterine leiomyosarcoma. Gynecol Oncol 122:255-259

5. Einstein MH, Barakat RR, Chi DS, Sonoda Y, Alektiar KM, Hensley ML et al (2008) Management of uterine malignancy found incidentally after supracervical hysterectomy or uterine morcellation for presumed benign disease. Int $\mathrm{J}$ Gynecol Cancer 18:1065-1070

6. Della Badia C, Karini H (2010) Endometrial stromal sarcoma diagnosed after uterine morcellation in laparoscopic supracervical hysterectomy. J Minim Invasive Gynecol 17:791-793

7. Laparoscopic uterine power morcellation in hysterectomy and myomectomy: FDA Safety Communication, April 17, 2014. (http://www. fda.gov/MedicalDevices/Safety/AlertsandNotices/ucm393576.htm)

8. AAGL report: Morcellation During uterine tissue extraction, May 2014 (http://www.aagl.org/wp-content/uploads/2014/05/Tissue Extraction_TFR.pdf)

9. Cohen SL, Greenberg JA, Wang KC, Srouji SS, Gargiulo AR, Pozner $\mathrm{CN}$ et al (2014) Risk of leakage and tissue dissemination with various contained tissue extraction techniques: an in vitro pilot study. J Minim Invasive Gynecol 21:935-939

10. Cohen SL, Einarsson JI, Wang KC, Brown D, Boruta D, Scheib SA, Fader AN, Shibley T (2014) Contained power morcellation within an insufflated isolation bag. Obstet Gynecol 124(3):491-497 